\title{
To Understand Well on the Source of COVID-19: Rhinolophus affinis-1
}

\section{Koyunoğlu C*}

Energy Systems Engineering Department, Engineering Department, Turkey

*Corresponding author: Cemil Koyunoğlu, Energy Systems Engineering Department, Engineering Department, Center Campus, 77200, Yalova, Turkey, Email: cemil.koyunoglu@ yalova.edu.tr

\section{Perspective \\ Volume 5 Issue 2}

Received Date: June 18, 2020

Published Date: August 10, 2020

DOI: $10.23880 /$ ijbp-16000179

\section{Abstract}

Genetic studies of the Rhinolophus affinis shown as the source of COVID-19 point to a species found primarily in China. It is essential to protect the population of this species in the World in order to prevent the decrease in the population of this species of bats, which plays an essential role in the pollination of plant foods that make up the human food sources because they are used in soup making. The most significant food sources of bats are; insects belonging to Chrysopidae and Hemerobiidae family, Cockroach insects, Dictyopterous and Dipterous insects and mosquitoes creates. For example; The giant brown bat alone can eat between 3000 and 7000 mosquitoes overnight. Bats combat their large populations annually by consuming more than millions of forest and agricultural pests and provide a unique benefit to ecology. Meanwhile, wet areas are also crucial for the continuation of ecological balance and the continuity of insects and bats. Because these areas regularly provide water and insect support, thus having a significant impact on the bat population. Bats are also vital for rainforests. Bats ensure that about 95 percent of the trees in this region reproduce by carrying pollen and seeds.

Keywords: Rhinolophus affinis; Bat; SARS-CoV-2

\section{Introduction}

Since the early events of COVID-19 are linked to the Huanan market in Wuhan, an animal resource likely exists in this area (Figures 1 and 2). Similarities in SARS-CoV-2 and bat SARS-CoV-like coronaviruses suggest that bats play a role as reservoirs. Although RaTG13, sampled from Rhinolophus affinis type bat, is 96\% similar to SARS-CoV-2, its protrusions in its RBB cannot be effectively linked to ACE2s in humans. Malayan pangolins (Manis javanica), which were illegally brought to the city of Guangdong, contain coronaviruses similar to SARS-CoV-2. While the RaTG13 bat virus is the virus closest to the SARS-CoV-2 genome, some pangolin coronaviruses have the strongest similarity to their RBB. This clearly shows that the SARS-CoV-2 spike protein is suitable for binding to human-like ACE2 and is a result of natural selection [1-8]. The important issue is the method of finding the source of the virus. Chou's 5 step rule is one of them [9]. Another method is various algorithms for welding (Figure 3) [10].

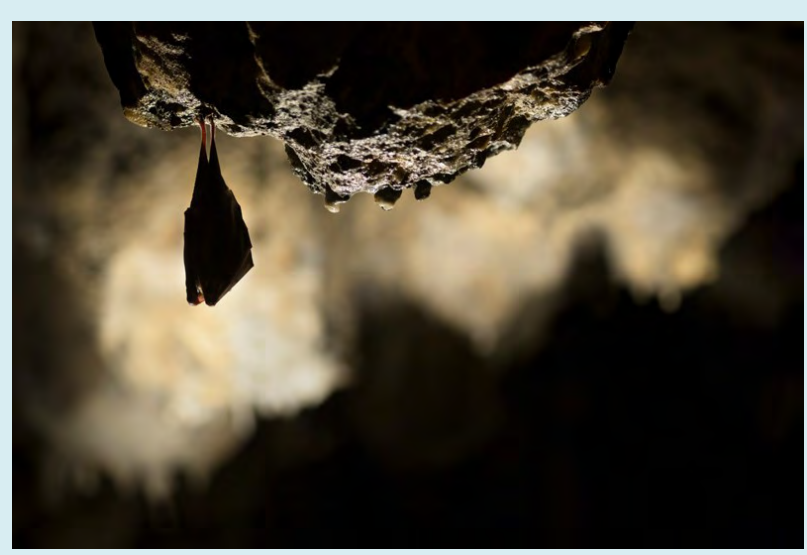

Figure 1: Studies refer to bats are sources of COVID-19 [4]. 


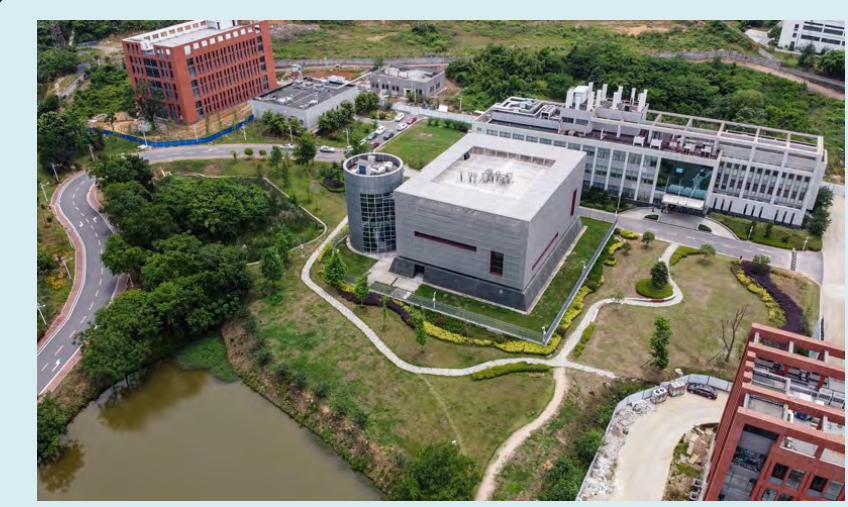

Figure 2: The Wuhan Institute of Virology in China [8].

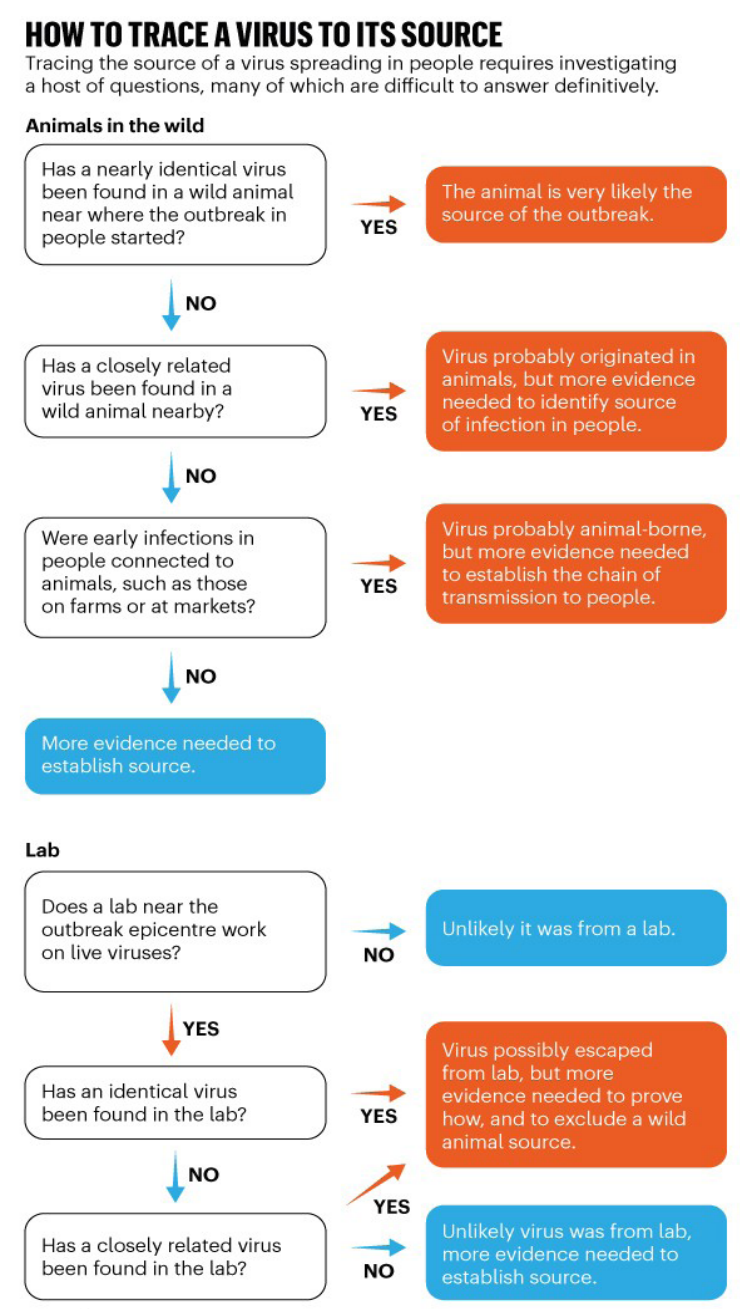

(c)nature

Figure 3: Routes to find COVID-19 virus [10].

An ancestor of SARS-CoV-2 is likely to have passed on to humans by gaining genomic features through adaptation.
Once this is possible, pandemics may arise as a result of these adaptations (Figure 4). The presence of an RBB in Pangolin, which is very similar to that in SARS-CoV-2, suggests that the same situation applies to the virus passed on to humans. Based on the current sequence data, the release date of the ancestor of the SARS-CoV-2 is the end of November 2019, and the beginning of December; these dates are compatible with the earliest confirmed case [11-17]. This bat species, which is the source of the COVID-19 virus transmitted from Rhinolophus affinis species bat, is only in the Asian region of the World [18]. Their populations are low.

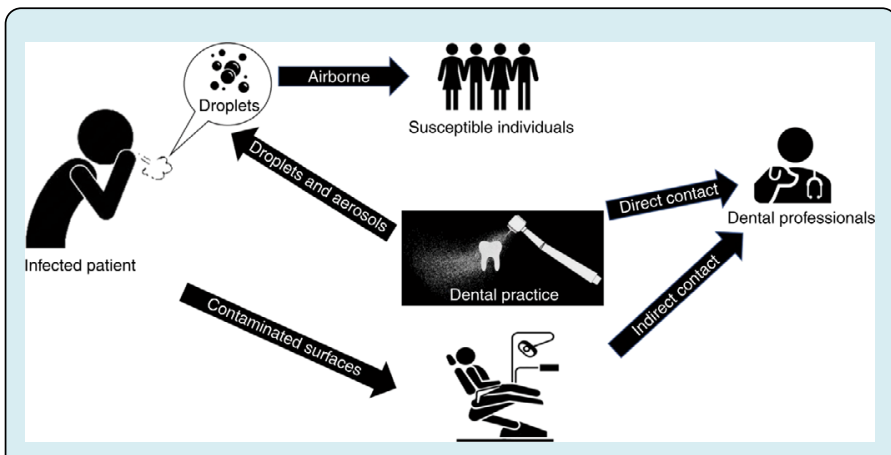

Figure 4: Transmission routes of 2019-nCoV in hospitals and also dental clinics [6].

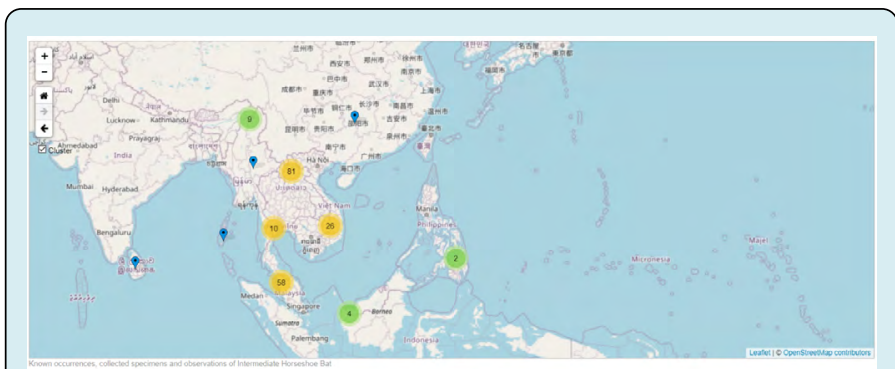

Figure 5: Rhinolophus Affini's population distribution in the World.

\section{Methodology}

A comprehensive assessment of coronaviruses in livestock and wildlife by examining bats in China may be a solution to this. In researches, when a virus almost similar to SARS-CoV-2 is found in a living thing, it is possible to have information about how the virus is passed on to humans. For the detailed approach see Figure 3.

It is clear that bat species contain many viruses, such as bats, which are thought to be COVID-19 hosts [13]. The distribution of Bat-CoVs, which are mostly called Betacoronavirus and Alphacoronavirus in the World, can be seen in Figure 6. Each colored region indicates the region where that coronavirus was discovered. Green zones indicate the country where Betacoronavirus was discovered, and red 


\section{International Journal of Biochemistry \& Physiology}

zones indicate the country where Alphacoronavirus was discovered. Red-green striped regions are regions with both types of viruses [13]. In a Hong Kong-based study between 2008-2017, the relationship between different bat species and different Alpha and beta coronavirus subspecies was investigated. And then, the transmission creatures were identified (Figure 7).

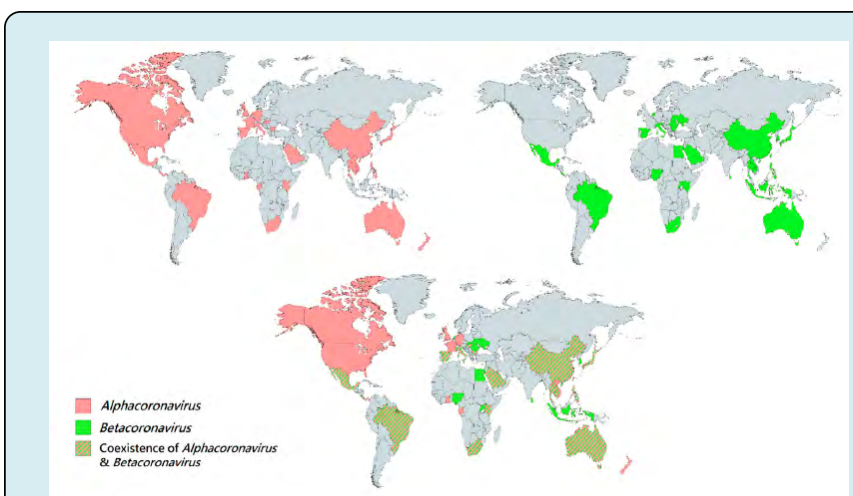

Figure 6: Viruses come from bats distribution in the World [13].

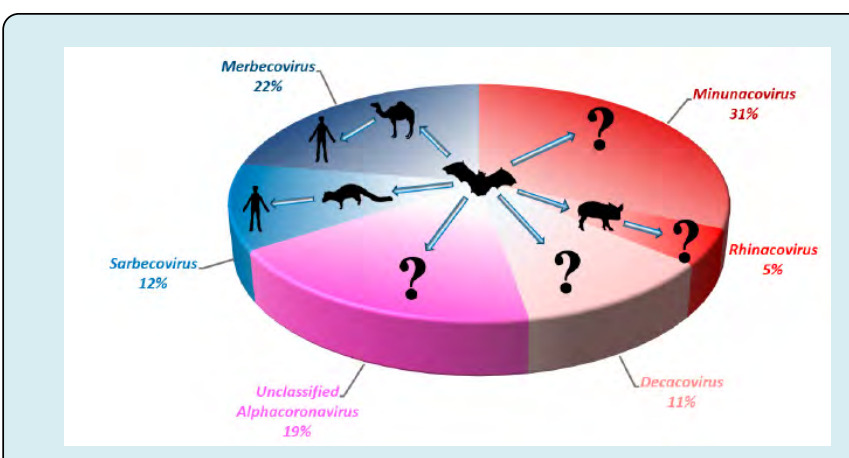

Figure 7: What is the transferred animal of the COVID-19? [13]

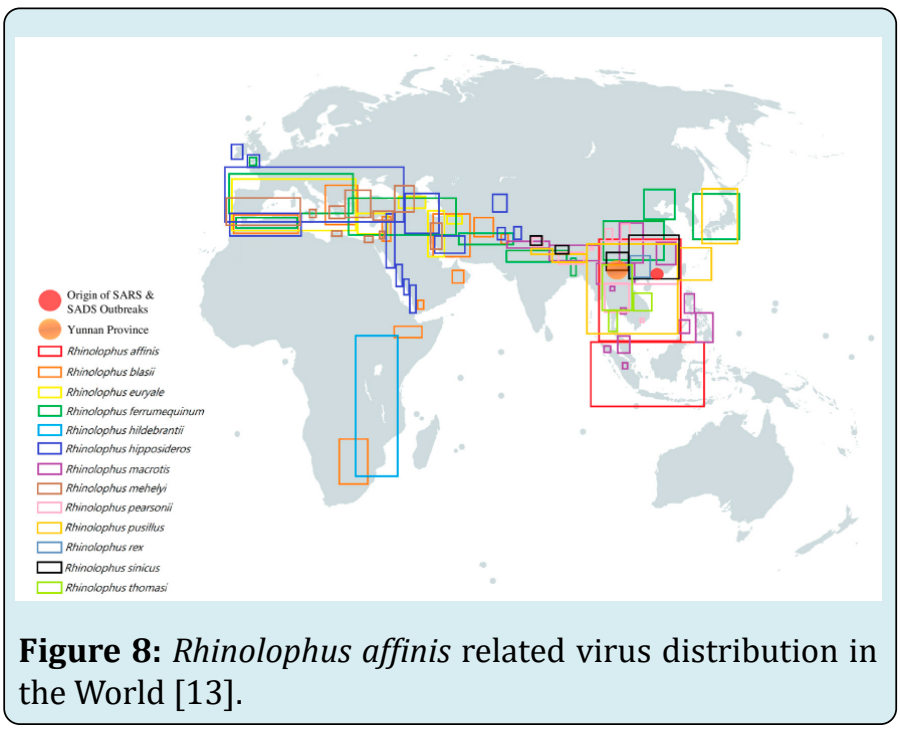

Alphacoronavirus not classified in the figure represents genome characterization and non-genome sequences. The betacoronavirus represents blue, and the alfacoronavirus represents red [13]. The distribution of Rhinolophus affinis, which is thought to be the source of COVID-19, is shown in Figure 8 as a red box. This type of horsebats is a subspecies of bats. Each colored rectangular box represents the geographic distribution of a particular type of horseshoe bat, respectively [13].

The red circle represents the origin of the SARS \& SADS outbreaks. The orange circle represents Yunnan Province. Lime can, Rhinolophus thomasi; green box, Rhinolophus ferrumequinum, Orange box, Rhinolophus blasii; purple box, Rhinolophus macrotis; yellow box, Rhinolophus euryale; turquoise box, Rhinolophus hildebrantii; golden box, Rhinolophus pusillus; indigo box, Rhinolophus hipposideros; brown box, Rhinolophus mehelyi; pink box, Rhinolophus pearsonii; blue-gray box, Rhinolophus rex; the black box represents Rhinolophus sinicus [13].

It is necessary to adapt the genomic characteristics of the transmission path before adaptation to humans. Depending on this, a pandemic may develop. A similar to SARS-CoV-2 has also been found in Pangolin. The exit time interval of SARS$\mathrm{CoV}-2$ is the earliest confirmed case, the end-of-December interval, at the end of November 2019 [13].

In Figure 9, the geographical distribution of Bat CoVs can be seen in betacoronavirus. Each colored region represents the country reporting the discovery of the $\mathrm{CoV}$ of bats of different subgenres. The navy regions represent countries that discovered bat CoVs from Sarbecovirus. The yellow regions represent countries that discovered bat CoVs from Merbecovirus. Purple regions represent countries that discovered bat CoVs from Nobecovirus [13].

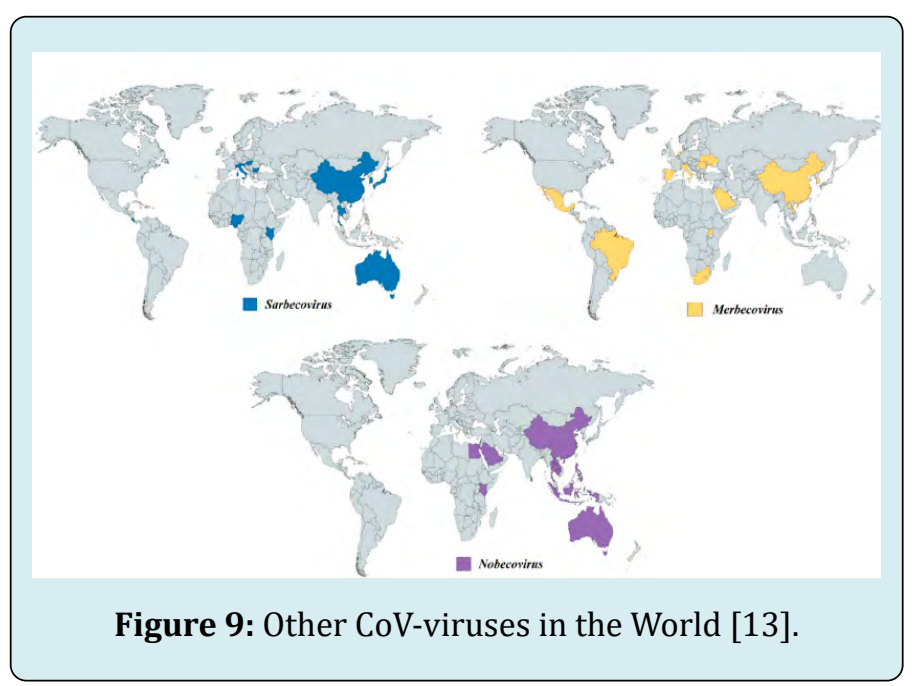




\section{International Journal of Biochemistry \& Physiology}

\section{References}

1. Andersen KG, Rambaut A, Lipkin WI, Holmes EC, Garry $\mathrm{RF}$ (2020) The proximal origin of SARS-CoV-2. Nature Medicine 26(4): 450-452.

2. Arai S, Aoki K, Son NT, Tú VT, Kikuchi F, et al. (2019) Đakrông virus, a novel mobatvirus (Hantaviridae) harbored by the Stoliczka's Asian trident bat (Aselliscus stoliczkanus) in Vietnam. Scientific Reports 9(1): 10239.

3. Lam S, Bordin N, Waman V, Scholes H, Ashford P, et al. (2020) SARS-CoV-2 spike protein predicted to form complexes with host receptor protein orthologues from a broad range of mammals. bioRxiv 2020: 2020.05.01.072371.

4. Liu Y, Hu G, Wang Y, Zhao X, Ji F, et al. (2020) Functional and Genetic Analysis of Viral Receptor ACE2 Orthologs Reveals a Broad Potential Host Range of SARS-CoV-2. bioRxiv 2020: 2020.04.22.046565.

5. Meng F, Zhu L, Huang W, Irwin DM, Zhang S (2016) Bats: Body mass index, forearm mass index, blood glucose levels and SLC2A2 genes for diabetes. Sci Rep 6(1): 29960.

6. Peng X, Xu X, Li Y, Cheng L, Zhou X, et al. (2020) Transmission routes of 2019-nCoV and controls in dental practice. International Journal of Oral Science 12(1): 9.

7. Zhou P, Fan H, Lan T, Yang XL, Shi WF, et al. (2018) Fatal swine acute diarrhoea syndrome caused by an HKU2related coronavirus of bat origin. Nature 556(7700): 255-258.

8. Zhou P, Yang XL, Wang XG, Hu B, Zhang L, et al. (2020) A pneumonia outbreak associated with a new coronavirus of probable bat origin. Nature 579(7798): 270-273.
9. Koyunoglu C (2020) Use Chou's 5-Steps Rule to Reveal Why SARS + MERS = COVID-19? Journal of Biochemistry and Analytical studies 4(2): 1-2.

10. Cyranoski D (2020) The biggest mystery: what it will take to trace the coronavirus source. Nature 2020.

11. Han Y, Du J, Su H, Zhang J, Zhu G, et al. (2019) Identification of Diverse Bat Alpha corona viruses and Betacoronaviruses in China Provides New Insights Into the Evolution and Origin of Coronavirus-Related Diseases. Front Microbiol 10: 1900.

12. Sia TJ, Zubaid A, Foo NY (2015) Population trends of Rhinolophus affinis during the breeding and non-breeding season roosting at the Kota Gelanggi limestone complex, Pahang. AIP Conference Proceedings 1678(1):020033.

13. Wong ACP, Li X, Lau SKP, Woo PCY (2019) Global Epidemiology of Bat Corona viruses. Viruses 11(2): 174.

14. Wu Z, Liu B, Du J, Zhang J, Lu L, et al. (2018) Discovery of Diverse Rodent and Bat Pestiviruses with Distinct Genomic and Phylogenetic Characteristics in Several Chinese Provinces. Frontiers in Microbiology 9(2562).

15. Rockett RJ, Arnott A, Lam C, Sadsad R, Timms V, Gray K-A, et al. Revealing COVID-19 transmission in Australia by SARS-CoV-2 genome sequencing and agent-based modeling. Nature Medicine 2020.

16. Xiao K, Zhai J, Feng Y, Zhou N, Zhang X, et al. (2020) Isolation of SARS-CoV-2-related coronavirus from Malayan pangolins. Nature 583(7815): 286-289.

17. Zhang X, Tan Y, Ling Y, Lu G, Liu F, et al. (2020) Viral and host factors related to the clinical outcome of COVID-19. Nature 583(7816): 437-440.

18. (2020) Eol. Intermediate Horseshoe Bat. 